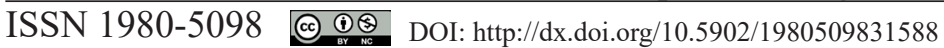

\title{
AVALIAÇÃO DO RENDIMENTO DA MATÉRIA-PRIMA NO PROCESSO PRODUTIVO DE PEÇAS CLEAR BLOCKS
}

\author{
EVALUATION OF YIELD OF RAW MATERIAL IN THE PRODUCTIVE \\ PROCESS OF CLEAR BLOCKS PIECES
}

\author{
Alexsandro Bayestorff da Cunha ${ }^{1}$ Ghislaine Miranda Bonduelle ${ }^{2}$ Bruna Laís Longo ${ }^{3}$
}

\begin{abstract}
RESUMO
O setor madeireiro é caracterizado por ser uma grande fonte de geração de desperdícios. Assim, o efetivo controle das atividades produtivas é condição indispensável para que qualquer empresa possa competir no mercado. O objetivo do estudo foi avaliar o rendimento da matéria-prima em termos percentuais e financeiros de uma indústria de Clear Blocks, com intuito de definir as melhores variáveis para fornecedor, bitola e destopadeira. A metodologia envolveu a seleção das variáveis de interesse: fornecedor (interno e externo); bitola (67 e $92 \mathrm{~mm}$ ) e destopadeira (corte de baixo para cima e de cima para baixo); a determinação do rendimento percentual total e por classe de qualidade através do balanço de material, e o financeiro através do custo da matéria-prima, custo de produção e preço de venda. A análise dos resultados foi realizada através da análise de variância multifatorial e teste de Tukey. O rendimento de matéria-prima em termos percentuais encontrado no estudo demonstrou a superioridade da bitola $92 \mathrm{~mm}$ frente a $67 \mathrm{~mm}$, em virtude do maior aproveitamento das peças. Quanto ao fornecedor, observou-se melhor desempenho do externo frente ao interno devido à qualidade da madeira, entretanto, em termos financeiros, esta situação foi inversa em função do menor custo da matéria-prima do fornecedor Interno. Para a forma de processamento da destopadeira, não foi verificado diferença estatística entre os dois sistemas de corte.

Palavras-chave: beneficiamento da madeira; fornecedores de matéria-prima; plaina e destopadeira.
\end{abstract}

\begin{abstract}
Wood sector is characterized by a great source of waste generation. This way, the effective control of the productive activities is an essential condition for any company to compete in the market. The objective of the study was to evaluate the yield of raw material in percentage and financial terms of a clear blocks industry, in order to define the best variables for supplier, size and edger. The method involved the selection of variables of interest, edgers (up-down and down-up cuts), size (67 mm and $92 \mathrm{~mm}$ ) and supplier (internal and external); the determination of the total percent yield and quality grade through the material balance and the financial means of the cost of raw materials, production costs and selling price. The analysis was performed by multifactorial analysis of variance and Tukey's test. The yield of raw materials in percentage terms found in the study demonstrated the superiority of the size $92 \mathrm{~mm}$ front and $67 \mathrm{~mm}$, because of the increased use of parts. Concerning to the supplier, it was observed a better performance of the sternum against internal due to the quality of the wood, however, in financial terms, this situation was reversed due to the lower cost of raw material for domestic supplier. To the form of processing in the edger, unverified

1 Engenheiro Florestal, Dr., Professor Associado do Departamento de Engenharia Florestal, Universidade do Estado de Santa Catarina, Av. Luiz de Camões, 2090, Conta Dinheiro, CEP 88520-000, Lages (SC), Brasil. alexsandro@udesc.br

2 Engenheira Florestal, Dra ${ }^{\mathrm{a}}$, Professora Associada do Departamento de Engenharia e Tecnologia Florestal, Universidade Federal do Paraná, Av. Pref. Lothário Meissner, 632, Jardim Botânico, CEP 80210-170, Curitiba (PR), Brasil. ghislaine@ufpr.br

3 Engenheira Florestal, MSc., Programa de Pós-graduação em Engenharia Florestal, Universidade do Estado de Santa Catarina, Av. Luiz de Camões, 2090, Conta Dinheiro, CEP 88520-000, Lages (SC), Brasil. bl2.woodtech@gmail.com
\end{abstract}

Recebido para publicação em 11/07/2012 e aceito em 13/01/2017

Ci. Fl., v. 28, n. 1, jan.- mar., 2018 
statistical difference between the two court systems.

Keywords: wood improvement; suppliers of raw material; planermills and edgers.

\section{INTRODUÇÃO}

A produção de produtos de maior valor agregado (PMVA) é fragmentada e diversificada no Brasil, sendo este setor dividido em quatro grandes segmentos: portas, molduras, pisos e painéis EGP (Edge Glued Panel). As molduras são peças perfiladas empregadas quase sempre para acabamentos interiores com propósito decorativo na construção civil. Estas peças são manufaturadas a partir da obtenção de peças denominadas de Clear Blocks, processo que gera grandes perdas de matéria-prima ao longo do fluxo de produção, sendo necessárias avaliações de qualidade contínuas para monitorar e/ou realizar ações preventivas. No Brasil, as molduras são fabricadas em sua maior parcela em madeira de pinus e normalmente são produtos para exportação. Existem inúmeros perfis de molduras, os quais estão associados as suas aplicações. Desta forma, as molduras assumem diferentes denominações, como por exemplo, meia-cana, rodapé, batente, vista de porta e janela.

O segmento de molduras mostrou constante evolução do volume produzido, como pode ser observado no período compreendido entre 1998 e 2007, no qual houve crescimento na produção interna de 530,8\%, representando crescimento médio anual de 22,7\%. Em se tratando de consumo, somente em 2004 foram obtidos valores significativos $\left(65 \mathrm{mil} \mathrm{m}^{3}\right)$, alcançando, em 2007, o volume de $212 \mathrm{mil} \mathrm{m}^{3}$. A partir desse fato, constata-se que a maior parte da produção desse produto é voltada ao mercado externo (ASSOCIAÇÃO BRASILEIRA DA INDÚSTRIA DA MADEIRA PROCESSADA MECANICAMENTE, 2009).

Em termos de processo, constata-se que o baixo rendimento nas empresas do setor de base florestal como serrarias e unidades de beneficiamento tem dificultado a competição, principalmente na exportação, pois ainda utilizam tecnologias ultrapassadas e maquinários que não proporcionam bons rendimentos, por estarem desgastados ou mesmo utilizando ferramentas de corte com espessuras elevadas (RIBAS, 1989).

Desta forma, pode-se afirmar que atualmente, o efetivo das atividades produtivas é condição indispensável para que qualquer empresa possa competir em igualdade de condições com seus concorrentes. Sem este controle, ou seja, sem a capacidade de avaliar o desempenho de suas atividades e de intervir rapidamente para a correção e melhoria dos processos, a empresa estará em desvantagem frente à competição mais eficiente (BORNIA, 1995). Isto tem levado as empresas a buscarem ferramentas que as auxiliem a melhorar sua produtividade, eficiência, aumentar fatias de mercado e lucratividade através da redução de custos, visando sempre atingir a satisfação total de seus clientes (CORAL, 1996).

De acordo com Cunha (2001), a contínua busca da qualidade pelas empresas é devida também à exigência dos mercados interno e, principalmente externo, que têm buscado certificados para seus produtos, processos, florestas, como os das séries ISO 9000, ISO 14000, FSC (Forest Stewardship Council). Porém, a certificação da qualidade é apenas o início de um longo caminho para a obtenção da excelência em processos e serviços.

Por sua vez, os clientes estão se tornando cada vez mais exigentes com relação à qualidade do produto e do seu processo produtivo, mesmo que isto ainda não seja caracterizado. O controle de qualidade se refere a um processo ou conjunto de atividades e técnicas operacionais que são empregadas para cumprir os requerimentos de qualidade. Essa definição implica em qualquer operação que sirva para melhorar, dirigir ou assegurar a qualidade (ROBERT, 2011).

A quantificação da má qualidade e eficiência de processo são pontos importantes e servem como base para a implantação de qualquer programa de melhoria para chegar a um nível ótimo de qualidade. 
A má qualidade está presente nos processos produtivos, principalmente nos que não possuem sistemas de qualidade. Entretanto, em muitos casos, não aparece nos sistemas contábeis, ficando embutida nos custos globais de produção.

O objetivo do presente estudo foi avaliar o rendimento da matéria-prima de uma Indústria de Clear Blocks, de modo a definir o melhor fornecedor de madeira serrada e o produto (bitola) que agrega maior valor no processo. Desta forma, buscou-se a obtenção de informações que melhorassem o aproveitamento dos recursos produtivos do setor e a qualidade da produção. Para tanto, foram definidas as seguintes metas: quantificar e caracterizar o rendimento total de matéria-prima em termos percentuais e financeiros ao longo de todo processo; determinar o rendimento de matéria-prima por classe de qualidade (Clear Blocks A, B e provenientes de retrabalho); avaliar as principais variáveis que afetam o beneficiamento das peças de Clear Blocks (destopadeira, bitola e fornecedor) e determinar quais os melhores níveis dentro destas variáveis.

\section{MATERIAL E MÉTODO}

O estudo foi desenvolvido em uma empresa situada no Planalto Norte de Santa Catarina, a qual tinha como produto principal peças de Clear Blocks para o mercado americano e europeu, sendo que a matéria-prima utilizada na produção era proveniente exclusivamente de reflorestamentos de Pinus taeda e Pinus elliottii.

A produção das peças iniciava com o desdobro das toras, passando pela secagem, pré-destopo e beneficiamento, em que as peças de madeira serrada passavam por uma plaina quatro faces que realizava a calibração em largura e espessura. Na sequência, as peças aplainadas eram destopadas com o objetivo de eliminar os defeitos naturais da madeira e os causados pelas operações anteriores (desdobro e secagem).

O processo de classificação adotado para as peças era visual, por ser um método simples e eficiente na identificação de defeitos como nós, desvio de grã, rachaduras e presença de medula, os quais afetam negativamente as propriedades mecânicas da madeira (FIORELLI; DIAS; COIADO, 2009). A qualificação dos defeitos era realizada nas 6 faces das peças, sendo separadas em bitolas (larguras) homogêneas, em Clear Blocks A e B, retrabalho e rejeitos. Após a classificação, os funcionários direcionavam as peças de qualidade A e B para o encaixotamento/embalagem e as demais para as operações de retrabalho. As classes de qualidade utilizadas na empresa eram as seguintes:

- Clear Blocks A: peças de madeira totalmente livre de defeitos;

- Clear Blocks B: peças que admitiam defeitos pouco significativos e toleráveis como azulamento, medula superficial em uma das faces, marca de plaina, bolsa de resina;

- Retrabalho: peças que possuíam defeitos passíveis de eliminação através redução da largura da peça, como por exemplo: largura $92 \mathrm{~mm}$, que tinha o defeito eliminado no retrabalho, podendo ser utilizada como 67 ou $48 \mathrm{~mm}$, dependendo da extensão do defeito.

- Rejeitos: peças de madeira com comprimento insuficiente, ou com defeitos significativos (exemplo: nós soltos, gravata e medula nas duas faces da peça) que inviabilizam as suas utilizações. Estas eram utilizadas nas caldeiras para geração de energia.

As peças que necessitavam ser retrabalhadas passavam por um refiladeira com o intuito de reduzir a largura, aumentando o aproveitamento das peças e reduzindo as perdas. Após a passagem pela refiladeira, as peças seguiam para a destopadeira de retrabalho e novamente para a classificação.

\section{Implantação do experimento}

As variáveis selecionadas para o estudo foram fornecedor, bitola e destopadeira. Na seleção dos fornecedores, procurou-se comparar o fornecedor Interno (serraria da empresa), que apresentava qualidade inferior aos demais, mas em contrapartida possuía um custo menor, com um fornecedor que apresentasse uma melhor qualidade de madeira (poucos defeitos, consequentemente maior rendimento), mesmo com um custo mais elevado, deste modo selecionou-se um fornecedor denominado Externo.

As larguras (bitolas) utilizadas na produção de Clear Blocks variam de empresa para empresa, conforme a necessidade do mercado. A empresa estudada trabalhava com 11 bitolas, sendo as bitolas $92 \mathrm{~mm}$ e $67 \mathrm{~mm}$ as mais produzidas, devido à demanda do mercado internacional. Desta forma, fez-se a análise das 
duas no presente estudo.

O processo de beneficiamento das peças era composto por duas plainas e 7 destopadeiras. Com relação às plainas, utilizou-se durante a coleta de dados somente uma delas, cuja capacidade produtiva era de 18.000 metros lineares por dia. Já as destopadeiras, tinham-se três trabalhando com corte no sentido inferior-superior e as demais no sentido oposto, necessitando de uma análise para verificação da eficiência das máquinas e dos funcionários. Assim, selecionou-se uma destopadeira com cada sentido de corte. Cabe destacar que durante a coleta de dados trabalhou-se com os mesmos funcionários nas máquinas, para evitar diferenças com relação à mão de obra.

O delineamento utilizado no experimento foi o delineamento inteiramente casualizado com arranjo fatorial, através do qual foi possível verificar os efeitos não somente das variáveis isoladas, mas também das suas interações (Tabela 1).

TABELA 1: Combinações das variáveis estudadas.

TABLE 1: Combination of the studied variables.

\begin{tabular}{cccc}
\hline Tratamento & Fornecedor & Bitola (largura) & Destopadeira \\
\hline 1 & Interno & $92 \mathrm{~mm}$ & Sentido baixo para cima \\
2 & Interno & $67 \mathrm{~mm}$ & Sentido baixo para cima \\
3 & Externo & $92 \mathrm{~mm}$ & Sentido baixo para cima \\
4 & Externo & $67 \mathrm{~mm}$ & Sentido baixo para cima \\
5 & Interno & $92 \mathrm{~mm}$ & Sentido cima para baixo \\
6 & Interno & $67 \mathrm{~mm}$ & Sentido cima para baixo \\
7 & Externo & $92 \mathrm{~mm}$ & Sentido cima para baixo \\
8 & Externo & $67 \mathrm{~mm}$ & Sentido cima para baixo \\
\hline
\end{tabular}

Em que: em virtude do tempo despendido para cada tratamento e a pouca variação entre eles, segundo amostras-piloto, adotaram-se 3 repetições para cada experimento, totalizando 24 amostras.

\section{Coleta de dados}

A obtenção dos dados foi baseada na medição das dimensões das peças em todas as etapas do processo, cuja metodologia envolveu a:

a) Medição das peças na entrada do setor: após a secagem e acondicionamento, as peças eram levadas para o pré-destopo e, nesta fase, conseguiam-se separar as pilhas de forma homogênea. Posteriormente à chegada da madeira no setor, mediram-se todas as peças com auxílio de um paquímetro e uma trena. Assim, obteve-se o volume do lote (pilha) de madeira antes da entrada no processo.

b) Medição das peças após a etapa de aplainamento: conhecendo-se o comprimento da peça na entrada do processo (primeira medição) e as dimensões de largura e espessura que elas deveriam ficar, calculava-se o volume de cada peça e do lote após o aplainamento.

c) Medição das peças após o destopo e a classificação: nesta etapa, o funcionário separava as peças destinadas à Classe $\mathrm{A}, \mathrm{B}$, retrabalho e as rejeito, as quais eram mensuradas para a determinação do volume das peças de cada classe de qualidade.

Após a medição, as peças de Clear Blocks A e B eram levadas para o setor de embalagem, e as destinadas ao retrabalho para a refiladeira, onde eram reaproveitadas e continuavam sendo acompanhadas para a finalização do estudo do lote.

d) Medições das peças após o retrabalho: nessa etapa obteve-se o volume das peças provenientes do retrabalho, além do rendimento na operação.

\section{Análise do rendimento total no processo}

A determinação do rendimento do processo foi feita com base no princípio do balanço de material, que consiste na determinação de todas as entradas (madeira serrada) e saídas (Clear Blocks A e B provenientes de destopadeiras e do retrabalho). Sendo assim, estabeleceu-se a relação porcentual entre a quantidade de 
produto que sai do processo e a quantidade de matéria-prima que entra no processo (BRAND et al., 2004). A análise em termos de aproveitamento da madeira é fundamental, mas como em qualquer empreendimento o fator financeiro sempre é o ponto principal.

O ponto de partida para a análise financeira foi a obtenção dos dados referentes ao custo da matériaprima colocada no setor, custo de produção e custo do retrabalho (Tabela 2), e a partir deles pode-se obter a margem de lucro alcançada em cada variável de interesse.

TABELA 2: Custo da matéria-prima e de produção de Clear Blocks.

TABLE 2: Cost of raw material and production of Clear Blocks.

\begin{tabular}{|c|c|c|c|c|c|c|c|c|c|}
\hline \multirow[t]{2}{*}{$\begin{array}{l}\text { Bitola } \\
(\mathrm{mm})\end{array}$} & \multirow[t]{2}{*}{$\begin{array}{l}\text { Classe de } \\
\text { Qualidade }\end{array}$} & \multicolumn{2}{|c|}{$\begin{array}{l}\text { Custo mat.- } \\
\text { prima }\left(\mathrm{R} \$ / \mathrm{m}^{3}\right)\end{array}$} & \multirow[t]{2}{*}{$\begin{array}{c}\text { Custo de } \\
\text { Produção } \\
\left(\mathrm{R} \$ / \mathrm{m}^{3}\right)\end{array}$} & \multicolumn{2}{|c|}{$\begin{array}{l}\text { Custo Total } \\
\qquad\left(\mathrm{R} \$ / \mathrm{m}^{3}\right)\end{array}$} & \multirow[t]{2}{*}{$\begin{array}{c}\text { Preço } \\
\text { Venda } \\
\left(\mathrm{R} \$ / \mathrm{m}^{3}\right)\end{array}$} & \multicolumn{2}{|c|}{$\begin{array}{l}\text { Margem de lucro } \\
\qquad\left(\mathrm{R} \$ / \mathrm{m}^{3}\right)\end{array}$} \\
\hline & & Int & Ext & & Int & Ext & & Int & Ext \\
\hline $92 / 67$ & A & 225 & 290 & 80 & 305 & 370 & 460 & 155 & 90 \\
\hline $92 / 67$ & B & 225 & 290 & 80 & 305 & 370 & 380 & 75 & 10 \\
\hline \multicolumn{10}{|c|}{ Retrabalho } \\
\hline $86 / 67$ & A & 225 & 290 & 90 & 315 & 380 & 460 & 145 & 80 \\
\hline $86 / 67$ & B & 225 & 290 & 90 & 315 & 380 & 380 & 65 & 00 \\
\hline 48 & A & 225 & 290 & 90 & 315 & 380 & 340 & 25 & -40 \\
\hline 48 & B & 225 & 290 & 90 & 315 & 380 & 340 & 25 & -40 \\
\hline
\end{tabular}

Para a realização da análise financeira, as peças foram separadas por classe de qualidade, bitola e fornecedor. Após a separação multiplicou-se a porcentagem encontrada em cada classe pela margem de lucro que ela apresentava, obtendo-se assim, a lucratividade em cada classificação separadamente. Os valores correspondentes ao retrabalho foram obtidos pelo somatório da lucratividade das suas peças.

$\mathrm{Na}$ análise estatística foi considerada para efeito de cálculo somente a lucratividade financeira encontrada para $1 \mathrm{~m}^{3}$ de madeira serrada processada.

\section{Análise do rendimento por classe de qualidade}

Na obtenção do rendimento total, tanto em porcentagem como em moeda, fez-se o somatório de todas as classes de qualidade: Clear Blocks A, B e as provenientes do retrabalho. Porém, nesta etapa, as análises foram separadas por classe de qualidade, de forma a verificar o quanto cada uma gera em termos percentuais e financeiros.

Os resultados de rendimento total e por classe de qualidade A e B em termos percentuais foram comparados com uma empresa do mesmo setor, denominada como Empresa W. Esta empresa, apesar de trabalhar com uma bitola diferente da analisada no presente estudo, $124 \mathrm{~mm}$, foi a única que forneceu dados quantitativos para comparação com os resultados encontrados.

Os dados foram submetidos à análise da variância multifatorial e quando necessário ao teste de Tukey com 95\% de probabilidade, conforme indicado por Cunha (2001).

\section{RESULTADOS E DISCUSSÃo}

\section{Rendimento total de matéria-prima}

Através da análise da Figura 1A, pode-se observar que os melhores rendimentos médios totais (\%) pertencem à matéria-prima do fornecedor Externo, a bitola $92 \mathrm{~mm}$ e a destopadeira $\mathrm{A}$ (destopa de cima para baixo). Esta verificação foi realizada somente isolando cada uma das variáveis, restando ainda as interações entre elas que são possíveis pela análise da variância com arranjo multifatorial. Esta análise permite ainda 
confirmar se as conclusões tiradas somente pelo cálculo da média são verdadeiras.

O rendimento médio de 50,2\%, quando comparado com o rendimento 53,9\% da Empresa W, mostra que o rendimento da empresa estudada está muito próximo ao de outra empresa do mesmo segmento. Esta comparação foi feita em duas bitolas diferentes, pois a empresa comparada (Empresa W) trabalha somente com a bitola $124 \mathrm{~mm}$ e sem reaproveitamento. Assim, por trabalhar sem reaproveitamento, a empresa seleciona a matéria-prima destinada ao produto, para evitar perdas excessivas.
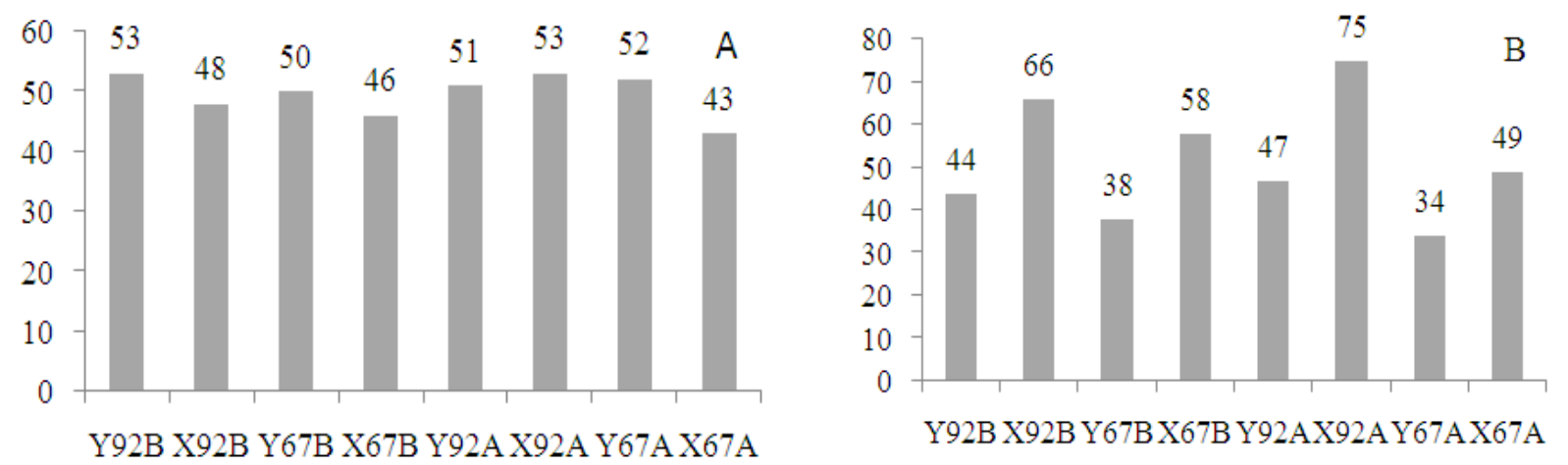

Em que: $\mathrm{X}=$ Fornecedor Interno; $\mathrm{Y}=$ Fornecedor Externo; Bitolas $=92$ e $67 \mathrm{~mm}$; Destopadeira $\mathrm{A}=$ destopa de cima para baixo; Destopadeira $\mathrm{B}=$ destopa de baixo para cima.

FIGURA 1: Rendimento Total de Matéria-Prima: (A) em percentual, (B) em $\mathrm{R} \$ / \mathrm{m}^{3}$.

FIGURE 1: Total Efficiency of the Raw Material: (A) in percentage, (B) in $\mathrm{R} \$ / \mathrm{m}^{3}$.

Realizando-se a análise da variância e teste de Tukey para as variáveis estudadas no rendimento total de matéria-prima (fornecedor, bitola e destopadeira), verificou-se que quanto ao fator destopadeira não houve diferença significativa, contrariando as conclusões preliminares, simplesmente pelo cálculo da média, no qual se observava a superioridade da destopadeira que corta de cima para baixo.

Contudo, com relação à bitola e o fornecedor, o teste de Tukey demonstrou que os melhores níveis foram a bitola $92 \mathrm{~mm}$ e o fornecedor Externo. A justificativa para a superioridade da bitola maior se deve ao amplo aproveitamento que estas peças têm no processo, pois esta largura é obtida diretamente na destopadeira sem retrabalho algum. Caso houvesse a presença de defeitos nas peças, elas ainda poderiam ser reaproveitadas na refiladeira nas larguras 67 e $48 \mathrm{~mm}$, eliminando os defeitos e possibilitando a comercialização destas peças. A bitola $67 \mathrm{~mm}$, caso precisasse ser trabalhada, só tinha a largura de $48 \mathrm{~mm}$ como opção, sendo o restante destinado à geração de energia.

Já o melhor desempenho da madeira do fornecedor Externo era esperado, pois visualmente notavamse as diferenças de qualidade entre as peças de madeira. Enquanto a madeira do fornecedor Externo tinha menor incidência de defeitos como nós, medula, rachadura, mancha química; a matéria-prima proveniente do fornecedor Interno tinha grande parte das peças com os defeitos supracitados.

A Figura 1B apresenta as médias das repetições de cada tratamento, as quais representam o lucro obtido a partir do beneficiamento de $1 \mathrm{~m}^{3}$ de madeira serrada, ou seja, o retorno financeiro proporcionado pelas peças A e B a partir do volume analisado.

A análise estatística para o rendimento financeiro demonstrou a superioridade da bitola 92 frente a $67 \mathrm{~mm}$ e do fornecedor Interno frente ao Externo.

No que tange à bitola, a diferença encontrada entre a $92 \mathrm{~mm}$ e a $67 \mathrm{~mm}$ deve ser repensada de maneira a aprimorar o aproveitamento da bitola menor, seja melhorando a habilidade dos destopadores e classificadores, colocando outras opções de bitola de retrabalho, ou ainda agregando um maior valor às peças como a produção de peças maiores através de uma emendadeira (Finger joint). A eliminação da produção das peças de $67 \mathrm{~mm}$, e o aumento da produção da bitola $92 \mathrm{~mm}$ ou outra qualquer com rendimento superior é inviável, pois qualquer indústria segue a tendência do mercado, ou seja, enquanto houver demanda e lucro, o produto é manufaturado. Assim, para que o rendimento da bitola $67 \mathrm{~mm}$ possa superar a $92 \mathrm{~mm}$, necessita-se aumentar sua produção, pois quanto maior a produção, menor o custo e maior 
o lucro, mas para isto ocorrer, deve haver uma demanda. A melhor solução seria a diminuição das perdas durante o processamento da madeira.

Quanto ao fator fornecedor, o teste de Tukey determinou o fornecedor Externo como o que apresenta melhor qualidade de matéria-prima. Mas, quando se trabalha em termos financeiros, verifica-se o inverso, este fornecedor apresenta menor margem de lucro. A grande causa é o custo da matéria-prima, pois a matéria-prima do fornecedor Externo custa R \$290,00 (preço da madeira serrada + transporte + secagem), a do fornecedor Interno custa $\mathrm{R} \$ 225,00$ (preço da tora + desdobro + secagem).

Portanto, devem-se tomar medidas em curto prazo para eliminação do fornecedor com preço elevado. Essa eliminação pode ser feita através de vários meios como negociação de preço junto a este fornecedor, busca de fornecedores alternativos que possuam matéria-prima de acordo com o padrão de qualidade da empresa, ou ainda aumentar a produção da Interna, o que necessitaria de novos investimentos em maquinários, espaço físico e mão de obra. Mas é importante destacar que estes investimentos são arriscados em virtude do setor apresentar uma demanda sazonal.

\section{Rendimento de matéria-prima por classe de qualidade}

A análise da produção por classe de qualidade está dividida em três partes principais, as quais englobam Clear Blocks A, Clear Blocks B e Clear Blocks A e B provenientes do retrabalho, expressas tanto em termos percentuais quanto em termos financeiros.

\section{Clear Blocks - classe A}

As médias dos rendimentos percentuais da linha Clear Blocks A estão apresentados na Figura 2A, na qual se evidencia novamente a superioridade da bitola $92 \mathrm{~mm}$ frente a $67 \mathrm{~mm}$ e o fornecedor Externo frente ao Interno. Estas diferenciações são significativas quando observadas na Análise da Variância. Através da comparação com outra empresa, tem-se 38,6\% das peças pertencentes à Linha $\mathrm{A}$ (Empresa W), enquanto que a empresa estudada apresenta $38,9 \%$ de suas peças destinadas diretamente para a Classe A. Além da produção obtida diretamente da destopadeira, tem-se ainda na empresa estudada a operação de retrabalho que aumenta o rendimento da matéria-prima no processo e a diferença de produção entre as duas empresas.
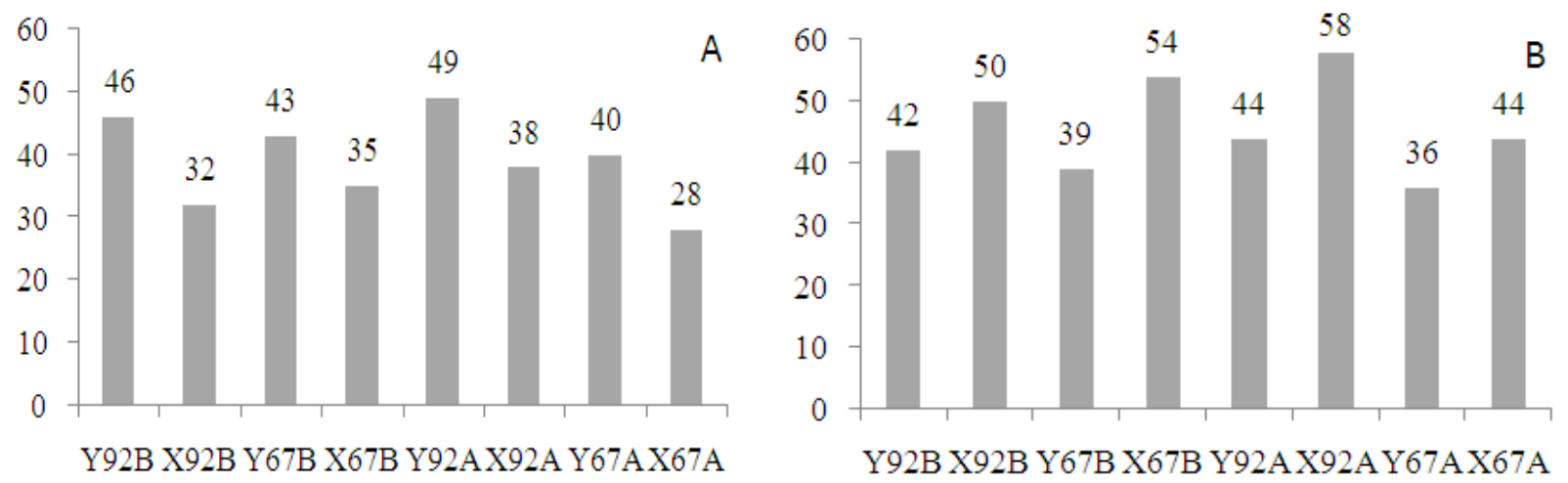

Em que: $\mathrm{X}=$ Fornecedor Interno; $\mathrm{Y}=$ Fornecedor Externo; Bitolas $=92$ e $67 \mathrm{~mm}$; Destopadeira $\mathrm{A}=$ destopa de cima para baixo; Destopadeira $\mathrm{B}=$ destopa de baixo para cima.

FIGURA 2: Rendimento de Clear Blocks A: (A) em percentual, (B) em R $\$ / \mathrm{m}^{3}$.

FIGURE 2: Efficiency of Clear Blocks A: (A) in percentage, (B) in $R \$ / \mathrm{m}^{3}$.

O teste de Tukey para o fator bitola demonstrou que a bitola $92 \mathrm{~mm}$ apresenta o rendimento de $41,4 \%$ para a Classe A, enquanto a bitola $67 \mathrm{~mm}$ o rendimento de $36,7 \%$. As duas grandes causas para esta diferença estão relacionadas à habilidade dos funcionários com as peças e à qualidade da matéria-prima. Quanto à primeira causa (habilidade do operador na destopadeira e do classificador), pode-se dizer que 
é devido à rapidez do trabalho e à necessidade de produção, em que o operador tem maior facilidade de identificar e retirar os defeitos na bitola $92 \mathrm{~mm}$, pois a visualização é mais fácil. Já na qualidade da matériaprima, a secagem e a qualidade da tora podem ser os principais fatores. Para o fator fornecedor, verificou-se que o melhor rendimento pertence ao fornecedor Externo com uma média de 44,7\%, demonstrando a sua superioridade sempre quando se analisa rendimento de matéria-prima, devido às condições como qualidade do reflorestamento e desdobro das peças.

Quanto ao aspecto financeiro, a classe A é a que apresenta maior margem de lucro, tendo em vista que apresenta o menor custo de produção por não necessitar de retrabalho. Pode-se dizer que esta classe chegaria a atingir $\mathrm{R} \$ 155,00$ de retorno para a empresa, se todo o volume de $1 \mathrm{~m}^{3}$ inicial fosse aproveitado somente em peças A; mas fazer esta afirmação não é possível, pois do volume de entrada, retiram-se ainda peças para Classe $\mathrm{B}$, peças a serem retrabalhadas e as perdas de matéria-prima ao longo do processo, as quais refletem diretamente no aumento do custo de produção e na diminuição dos ganhos da empresa.

Através da análise da Figura 2B, pode-se observar principalmente a superioridade do fornecedor Interno frente ao Externo, que apresenta as maiores médias em todos os experimentos, quando comparada com o fornecedor Externo. Esta situação mostra o inverso do verificado na análise realizada em termos de rendimento percentual de matéria-prima.

A superioridade da bitola $92 \mathrm{~mm}$ frente à bitola $67 \mathrm{~mm}$ para a Linha A, é confirmada pelo teste de Tukey da análise financeira. A causa desta diferença é um reflexo direto no rendimento em percentagem, pois o cálculo da margem de lucro das peças de Clear Blocks é baseado nesta análise. Pode-se dizer que não existem diferenças de preço entre uma bitola ou outra, pois ambas têm um custo por metro cúbico de matéria-prima de $\mathrm{R} \$ 225,00, \mathrm{R} \$ 80,00$ de produção e $\mathrm{R} \$ 115,00$ de venda para o fornecedor Interno, ou seja, a grande responsável pela superioridade da bitola $92 \mathrm{~mm}$ é a qualidade da matéria-prima beneficiada no processo.

Como citado, a classe de Clear Blocks A é a que fornece maior retorno financeiro à empresa, pois a $B$ alcança somente $R \$ 75,00 / \mathrm{m}^{3}$ de valor de mercado, e as provenientes de retrabalho, mesmo sendo classificadas posteriormente como "A", têm maior custo de produção. Ainda assim, este custo adicional de retrabalho $\left(\mathrm{R} \$ 10,00 / \mathrm{m}^{3}\right)$ compensaria se as peças fossem aproveitadas como A.

Com relação ao fornecedor, verifica-se que o maior rendimento de matéria-prima pertence ao fornecedor Externo para a Linha A. Porém, no teste de Tukey da análise financeira, nota-se que o fornecedor Interno apresenta o melhor desempenho financeiro, com média de R \$ 51,71 de margem de lucro.

Com esta análise, pode-se dizer que a utilização da matéria-prima com melhor qualidade e alto custo não é viável para a produção de Clear Blocks na empresa estudada; devendo-se utilizar o máximo possível de madeira do fornecedor Interno, ou de fornecedores com preço inferior para que se possa conseguir a maior margem de lucro.

\section{Clear Blocks - classe B}

Como se observa na Figura $3 \mathrm{~A}$, o rendimento médio correspondente à Classe $\mathrm{B}$ é pequeno $(3,5 \%)$, quando comparado com o rendimento da Classe A e das peças destinadas a retrabalho. Comparando com os resultados da Empresa W (15,3\%), verifica-se a superioridade em relação à empresa estudada, a qual pode estar em função da baixa qualidade da matéria-prima da primeira ou não ao reaproveitamento das peças da segunda, não proporcionando maior quantidade de peças na Classe $\mathrm{A}$.

A razão para o baixo rendimento de Clear Blocks da Classe B está em função do baixo valor que alcança no mercado. As diferenças significativas encontradas são principalmente relacionadas à bitola $\mathrm{e}$ ao fornecedor. Na análise da variância da Classe B, observou-se a diferença significativa da interação bitola-fornecedor, da qual se fez uma nova Análise da Variância específica e um novo teste de Tukey, os quais confirmaram a superioridade da bitola $92 \mathrm{~mm}$ e do fornecedor Externo em termos de rendimentos percentuais de matéria-prima, ou em alguns casos na interação bitola-fornecedor.

Mas não se pode pensar isoladamente, deve-se analisar em termos do processo integral (destopadeira - bitola - fornecedor), desta forma, não ocorre diferença significativa entre as variáveis do estudo. Mesmo assim, pode-se melhorar a matéria-prima do fornecedor Interno, através da melhoria da qualidade dos reflorestamentos e do processo de desdobro; também procurando explorar novos mercados, 
pois, mesmo não apresentando diferenças significativas no processo integral, pode render mais em termos financeiros para a empresa, mesmo que para isso seja necessário investir em equipamentos e funcionários, pois o mercado madeireiro está cada vez mais competitivo e só permanecerão no mercado as empresas que se destacarem.
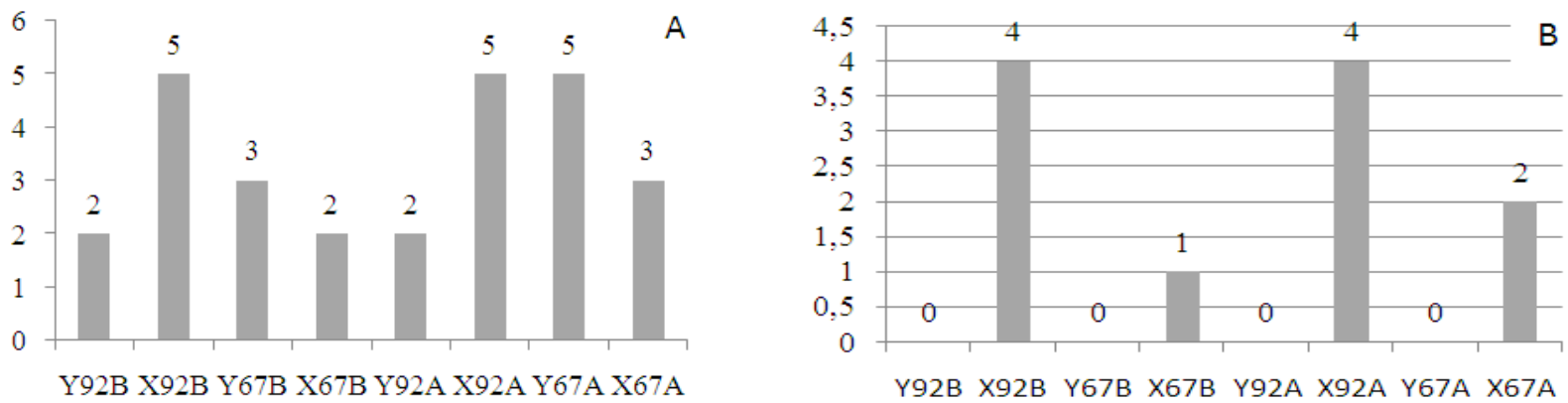

Em que: $\mathrm{X}=$ Fornecedor Interno; $\mathrm{Y}=$ Fornecedor Externo; Bitolas $=92$ e $67 \mathrm{~mm}$; Destopadeira $\mathrm{A}=$ destopa de cima para baixo; Destopadeira $\mathrm{B}=$ destopa de baixo para cima.

FIGURA 3: Rendimento de Clear Blocks B: (A) em percentual, (B) em R $\$ / \mathrm{m}^{3}$. FIGURE 3: Efficiency of Clear Blocks B: (A) in percentage, (B) in $R \$ / \mathrm{m}^{3}$.

Mas não se pode pensar isoladamente, deve-se analisar em termos do processo integral (destopadeira - bitola - fornecedor), desta forma, não ocorre diferença significativa entre as variáveis do estudo. Mesmo assim, pode-se melhorar a matéria-prima do fornecedor Interno, através da melhoria da qualidade dos reflorestamentos e do processo de desdobro; também procurando explorar novos mercados, pois, mesmo não apresentando diferenças significativas no processo integral, pode render mais em termos financeiros para a empresa, mesmo que para isso seja necessário investir em equipamentos e funcionários, pois o mercado madeireiro está cada vez mais competitivo e só permanecerão no mercado as empresas que se destacarem.

A Figura 3B deixa evidente o maior rendimento obtido com a matéria-prima do fornecedor Interno e um equilíbrio entre as médias da bitola e da destopadeira.

$\mathrm{Na}$ Análise de Variância, verificou-se que os fatores que apresentaram diferença significativa foram bitola, fornecedor e a interação entre eles.

O teste de Tukey para o fator bitola mostra que a bitola $92 \mathrm{~mm}$ apresenta retorno financeiro superior à bitola $67 \mathrm{~mm}$, em função da maior dimensão em largura, e consequente maior possibilidade da ocorrência de defeitos, mesmo alguns podendo ser eliminados no retrabalho, outros acabam permanecendo na Classe B. Quanto ao fator fornecedor, o teste de Tukey demonstrou a superioridade do fornecedor Interno. Isto é consequência do rendimento financeiro deste fornecedor ser de $\mathrm{R} \$ 2,70$, demonstrando que para cada metro cúbico de madeira serrada que entra no processo, a Linha Clear Blocks B apresenta esta margem de lucro; já o fornecedor Externo não apresenta rendimento. Em ambos os casos, têm-se poucas peças nesta classe devido ao baixo preço conseguido no mercado internacional, que é o principal mercado do produto estudado.

A grande diferença entre os fornecedores também é causada pela qualidade da matéria-prima do fornecedor Externo, que é superior ao outro, tendo a maioria das suas peças destinadas a Linha A, restando muito poucas para "B".

Na nova Análise da Variância trabalhou-se separadamente com a interação bitola-fornecedor, na qual se verificou a presença da diferença significativa, sendo resultante das altas diferenças encontradas nas duas variáveis isoladas, e ainda quando elas interagem uma com a outra, a diferença torna-se ainda maior.

No teste de Tukey, observa-se que a bitola $92 \mathrm{~mm}$ do fornecedor Interno é a que propicia o maior retorno financeiro para a empresa com média de $\mathrm{R} \$ 4,10$, muito superior às demais, como é evidenciado na análise dos contrastes. 


\section{Clear blocks - retrabalho}

A última forma de aproveitamento da matéria-prima gera o rendimento médio percentual de matéria-prima de 7,8\% (Figura 4A), que é superior ao obtido pela Linha B. Mesmo esta fase necessitando do emprego de outros maquinários e funcionários, gerando mais custos para a empresa, vale a pena o retrabalho em função da grande quantidade de peças com defeitos e do retorno financeiro que esta operação propicia. Salienta-se que nesta Linha não se compararam os resultados com a Empresa W, pois esta não possui a operação de retrabalho das peças de Clear Blocks.

A análise da variância para o rendimento percentual demonstra que existem diferenças significativas somente nos fatores destopadeira e fornecedor.

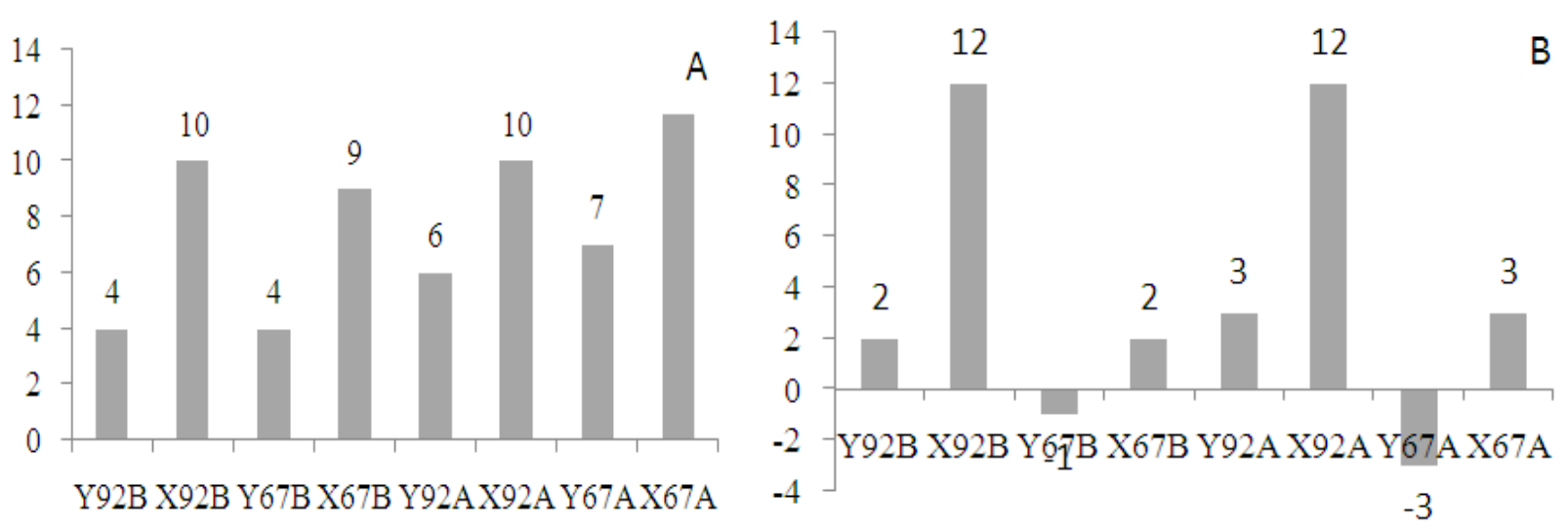

Em que: $\mathrm{X}=$ Fornecedor Interno; $\mathrm{Y}=$ Fornecedor Externo; Bitolas $=92$ e $67 \mathrm{~mm}$; Destopadeira A = destopa de cima para baixo; Destopadeira $\mathrm{B}=$ destopa de baixo para cima.

FIGURA 4: Rendimento de Clear Blocks - Retrabalho: (A) em percentual, (B) em R $\$ / \mathrm{m}^{3}$.

FIGURE 4: Efficiency of Clear Blocks - Rework: (A) in percentage, (B) in $R \$ / \mathrm{m}^{3}$.

A causa que originou a diferença entre os fornecedores foi devido à qualidade da madeira que estava sendo processada no momento da coleta de dados. Quanto ao teste de Tukey do fator fornecedor, evidencia-se a superioridade do fornecedor Interno. O maior responsável pela ocorrência da situação inversa ao observado até o momento é o fato de que o fornecedor Externo tem a maior parte das suas peças classificadas como Clear Blocks A, restando poucas para o retrabalho, ocorrendo o oposto com o fornecedor Interno, pois restam muitas para serem retrabalhadas na refiladeira e destopadeira. Assim, nesta análise, quanto menor a porcentagem de peças significa maior quantidade de peças classificadas na Classe A, ou seja, menor custo de produção e maior margem de lucro para a empresa.

$\mathrm{O}$ fornecedor Interno e a bitola $92 \mathrm{~mm}$ apresentam os melhores rendimentos financeiros das peças provenientes do retrabalho como demonstra a Figura 4B, enquanto a destopadeira demonstra o equilíbrio de produção, sem apresentar qualquer sinal significativo.

Observam-se nesta figura dois rendimentos negativos, ambos na bitola $67 \mathrm{~mm}$ e fornecedor Externo. A causa para esse fato é devido à produção de peças com bitola $48 \mathrm{~mm}$ que tem o custo de produção de $\mathrm{R} \$$ $380,00 / \mathrm{m}^{3}$ e o preço de venda de $\mathrm{R} \$ 340,00 / \mathrm{m}^{3}$, ou seja, perda de $\mathrm{R} \$ 40,00$. Já o fornecedor Interno tem o custo de produção de $\mathrm{R} \$ 315,00 / \mathrm{m}^{3}$ com o mesmo preço de venda, fornecendo o lucro de $\mathrm{R} \$ 25,00 / \mathrm{m}^{3}$.

A confirmação da significância é comprovada pela Análise da Variância, na qual se verifica que, além dos fatores já mencionados, tem-se a interação entre eles, o que demonstra que ocorrem fortes diferenças entre os níveis dos fatores estudados.

O teste de Tukey para o fator bitola mostra a grande superioridade da bitola $92 \mathrm{~mm}$ com diferença de $\mathrm{R} \$ 7,22 / \mathrm{m}^{3}$ da bitola $67 \mathrm{~mm}$, sendo esta causada diretamente pelo aproveitamento que as bitolas têm no retrabalho, ou seja, a bitola $92 \mathrm{~mm}$ pode ser retrabalhada na bitola $67 \mathrm{~mm}$ que tem o preço de venda de R\$ $460,00 / \mathrm{m}^{3}$ quando proveniente de retrabalho e na bitola $48 \mathrm{~mm}$ com o preço de venda de $\mathrm{R} \$ 340,00 / \mathrm{m}^{3}$, o 
que muitas vezes é inferior ao custo de produção, como já foi apresentado no estudo. Já a bitola $67 \mathrm{~mm}$ só tem a opção de retrabalho na bitola $48 \mathrm{~mm}$, que, quando oriunda de peças do fornecedor Externo, ao invés de gerar lucro, tem-se prejuízo com o beneficiamento destas.

Como consequência, tem-se o maior volume de produção proveniente do retrabalho da bitola 92 $\mathrm{mm}$ e também o maior retorno financeiro com o beneficiamento destas peças.

A empresa estudada, após o estudo, eliminou a bitola $48 \mathrm{~mm}$, a qual foi substituída pela bitola 54 $\mathrm{mm}$, que tem o mesmo preço de venda das demais bitolas $(67$ e $92 \mathrm{~mm})$. O reaproveitamento em matériaprima, passando de $48 \mathrm{~mm}$ para $54 \mathrm{~mm}$ foi menor, mas em compensação com margem de lucro maior.

O fornecedor que apresenta melhor rendimento financeiro no retrabalho é o Interno em virtude da maior quantidade de peças trabalhadas nesta operação ser proveniente deste e também devido ao alto custo da matéria-prima do Externo, que inviabiliza o beneficiamento de Clear Blocks, principalmente no retrabalho da bitola $67 \mathrm{~mm}$ em $48 \mathrm{~mm}$ no fornecedor Externo, pois apresenta resultado financeiro negativo de $\mathrm{R} \$ 40,00 / \mathrm{m}^{3}$. Assim, a madeira do fornecedor Interno, mesmo com qualidade inferior, consegue obter lucro até no retrabalho com as peças de $48 \mathrm{~mm}$ de largura, o que não é conseguido pelo outro fornecedor.

A nova Análise da Variância e o teste de Tukey, que refletem as interações, evidenciam a bitola 92 $\mathrm{mm}$ e o fornecedor Interno como a melhor interação e a bitola $67 \mathrm{~mm}$ com o fornecedor Externo como a pior interação.

Em todas as análises, observa-se que a única interação que apresentou diferença significativa é a interação bitola-fornecedor e os fatores que apresentaram maior diferenciação, quando analisados sozinhos são os mesmos da interação. Assim, pode-se dizer que o modelo da destopadeira pouco influi no processo produtivo, o que realmente conta é o maior rendimento financeiro que o fornecedor Interno atingiu e o rendimento tanto percentual quanto financeiro que a bitola $92 \mathrm{~mm}$ fornece.

\section{CONSIDERAÇÕES FINAIS}

O estudo do rendimento total de matéria-prima apontou em termos percentuais a bitola $92 \mathrm{~mm}$ e o fornecedor Externo, e em moeda a bitola $92 \mathrm{~mm}$ e o fornecedor Interno como os melhores níveis. Quanto à destopadeira, não há diferença significativa entre os modelos estudados, pois ambos apresentaram rendimentos semelhantes nos dois estudos.

A linha Clear Blocks A apresentou os melhores rendimentos novamente, os níveis bitola $92 \mathrm{~mm}$ e o fornecedor Externo para rendimento percentual e a bitola $92 \mathrm{~mm}$ e o fornecedor Interno para rendimento financeiro.

A linha Clear Blocks B foi a que proporcionou os piores retornos para a empresa, tanto em termos percentuais como financeiros. Mesmo assim, o melhor nível foi a interação bitola $92 \mathrm{~mm}$ e fornecedor Interno para rendimento percentual e os fatores isolados bitola $92 \mathrm{~mm}$ e fornecedor Interno para rendimento financeiro.

O retrabalho de Clear Blocks elimina uma porcentagem significativa de perdas. No rendimento percentual das peças oriundas desta atividade tem-se o fornecedor Interno como o melhor nível. Quanto ao rendimento financeiro, a bitola $92 \mathrm{~mm}$ e o fornecedor Interno, além da interação entre estas variáveis, destacaram-se como os melhores níveis.

Com relação ao estudo de rendimento, evidenciaram-se diferenças significativas principalmente nos fatores isolados, e algumas interações entre dois fatores, nunca os três, indicando que não há influência dos fatores quando trabalhados em conjunto.

\section{REFERÊNCIAS}

ASSOCIAÇÃO BRASILEIRA DA INDÚSTRIA DA MADEIRA PROCESSADA MECANICAMENTE. Estudo Setorial 2009 - Ano Base 2008. Curitiba: ABIMCI, 2009, p. 45.

BORNIA, A. C. Mensuração das perdas dos processos produtivos: uma abordagem metodológica do controle interno. 1995. 125 f. Tese (Doutorado em Engenharia de Produção) - Universidade Federal de Santa Catarina, Florianópolis, 1995.

BRAND, M. A. et al. Avaliação do processo produtivo de uma indústria de manufatura de painéis por 
meio do balanço de material e do rendimento da matéria-prima. Revista Árvore, Viçosa, MG, v. 28, n. 4 , p. 553-562, 2004.

CORAL, E. Avaliação e gerenciamento dos custos da não qualidade. 1996. 152 f. Dissertação (Mestrado em Engenharia de Produção) - Universidade Federal de Santa Catarina, Florianópolis, 1996.

CUNHA, A. B. Avaliação do processo produtivo de uma indústria de clear blocks na Região Sul do Brasil. 2001. 131 f. Dissertação (Mestrado em Engenharia Florestal) - Universidade Federal do Paraná, Curitiba 2001.

FIORELLI, J.; DIAS, A. A.; COIADO, B. Propriedades mecânicas de peças com dimensões estruturais de Pinus spp: correlação entre resistência à tração e classificação visual. Revista Árvore, Viçosa, MG, v. 33, n. 4, p. 741- 750, 2009.

RIBAS, C. et al. Estudo da influência do diâmetro e do comprimento das toras de Pinus elliottii na produção de madeira serrada e de resíduos de serraria. Revista Instituto Florestal, São Paulo, v. 1, n. 1, p. 50-65, 1989.

ROBERT, R. C. G. Controle de qualidade nas indústrias madeireiras e moveleiras. Revista da Madeira, Curitiba, v. 104, abr. 2011. 